\title{
THE NUCLEAR POWER DEBATE
}

\section{Present Disposal Technology Is Adequate To Contain Radwaste, But Misinformation Promotes The More Hazardous Alternative}

\section{BY DOUGLAS G. BROOKINS}

\section{Doug Brookins is Professor of Geology at the} University of New Mexico. He has long been a leading figure in the Materials Research Society's organization of topical symposia on the subject of radioactive-waste disposal. In 1982 he was Chairman of the Sixth International Symposium on the Scientific Basis for Nuclear Waste Management, and he chaired the session on research relevant to salt as a radwaste geomedium at the Seventh Symposium in Boston last November. In this essay, Prof. Brookins speaks from his professional perspective to document the safety of present radwaste disposal technology, and argues that nuclear power is especially attractive when compared with the prevailing alternative-energy generated by burning coal.

Recently the U.S. Supreme Court upheld a California moratorium on the construction of new nuclear power plants. While the reasons given were supposedly based on economic concerns and, in large part, on the lack of approved repositories for radioactive waste, the decision seems yet another example of the successful campaign of anti-nuclear advocates to thwart nuclear power development in this country. The paranoia surrounding nuclear energy is revealed strikingly in this instance, as Justices Harry A. Blackmun and John P. Stevens write that, even had the moratorium been based on fears of core meltdown or some other catastrophe, it would still have been valid. In the State of California, therefore, the development of nuclear power has been blocked still further.

This is unfortunate and unwarranted. Certainly on the issue of radwaste disposal, the evidence clearly supports nuclear power development. Moreover, the unenviable environmental record of coal, the power-generation alternative, compares quite unfavorably. In this regard, I find it interesting that, while much is made of the fact there have been some 90 or so nuclear power plant cancellations in recent years, one rarely hears of the similar cancellations of coal-fired plants in the same period. The answer to these mass cancellations lies largely with the fact that estimates made in the early 1970 s of a seven percent to nine percent annual increase over a 20-year span in electric energy consumption have proved to be wrong. Due to a great many reasons, electrical consumption slumped to around a one percent rate of growth in the early 1980s, and is now projected to grow no more than about three percent a year for the next several years.

\section{Radioactive Storage in Rocks}

There seems to be a public perception that radioactive substances are so destructive they can't be stored in rocks. Nature has been doing it for billions of years. Perhaps the best example is the Oklo Natural Reactor in Gabon which, some two billion years ago, acted as a nuclear reactor and, subsequently, a radioactive waste repository. There, copious amounts of fission products-uranium, transuranics, and actinide daughter elements-either remained where they were formed or migrated no more than a few meters. All of this

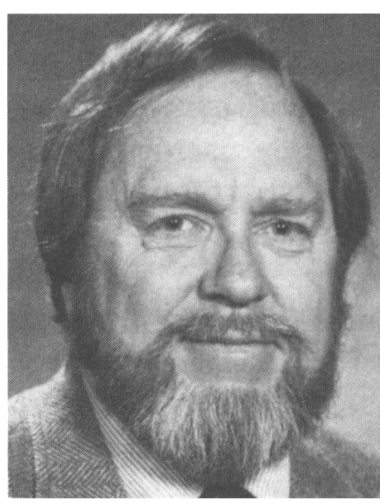

DOUGLAS BROOKINS occurred at a depth of 2,000 meters. At this remarkable site, rocks indeed contained their radioactive waste.

Also, most people are aware that the age of rocks and minerals can be determined by radiometric means; indeed, geochronologists have been doing this successfully since the early part of the 20th Century. What does this reveal about radioactive waste containment? Let us assume for hypothetical consideration a rock such as granite, of an age of one billion years. This granite can be dated by numerous geochronological methods-U-Pb, Th-Pb, Rb-Sr, K-Ar, Sm$\mathrm{Nd}, \mathrm{U}-\mathrm{Ru}, \mathrm{K}-\mathrm{Ca}, \mathrm{Lu}-\mathrm{Hf}, \mathrm{Re}-\mathrm{Os}$, to list the tried and true methods. Should all these methods yield concordant ages then, very simply, this rock has been closed to all these elements since formation. Hence, actinides, actinide daughters, alkali and alkaline earths, rare earths, noble gas, noble metals-all have remained isolated where formed. Even when some ages are discordant, the migration of elements (usually daughters) is on the order of millimeters.

Further, when molten rock intrudes other rocks, the heat provides an incredibly high thermal gradient which, in theory, can support elemental transfer from intrusive into intruded rocks. Such cases are natural analogs for buried radwaste, though these temperatures (on the order of 800$1000^{\circ} \mathrm{C}$ ) are much more extreme than those in relatively low-temperature radwaste containers. Yet studies continue to show that, effectively, little or no transfer takes place, even after thousands, tens of thousands, even hundreds of thousands of years. Rocks have contained the elements present in radioactive wastes. They can and will continue to contain them.

Scientists in the main have been convinced by this 
evidence. A National Science Foundation-funded study by Princeton University two years ago found that 83 percent of workers in the radwaste area agree that present technology is effective in the safe control of these wastes. The research of Rothman and Lichter (see "The Nuclear Energy Debate: Scientists, the Media and the Public," Public Opinion, August-September 1982) shows that scientists support nuclear power, and that the opinions of such groups as the Union of Concerned Scientists are reported out of proportion to their numbers.

\section{A Back-Door Endorsement of Coal}

The role of the media in reporting the nuclear-power controversy amounts to a back-door endorsement of coal. Given the stated concerns about health and the environment, this is a paradox. Can the nuclear industry be accused of contributing to as many deaths? A death due to radioactivity in a nuclear power plant would be a major story, would there be one. There hasn't. A death in a coal mine, however lamentable, is not very remarkable. There are too many.

The Office of Technology Assessment reported (July 1982) that as many as 51,000 premature deaths annually may be due to $\mathrm{SO}_{2}$ inhalation from emissions from coal-fired power plants. Add to these the number of premature deaths due to other oxides (mainly carbon and nitrogen), the long- range effects of large quantities of carcinogenic trace elements concentrated in coal that are released during burning, the suffering of miners from black lung and other respiratory ailments, the plight of roughly one quarter of the contiguous United States from acid rain, the ever-drawingnearer greenhouse effect, and the plethora of adverse health effects associated with the transportation and processing of coal, and one is baffled as to how the role of villain was assigned, and for what reasons.

Very obviously, the media and the public fear some kind of nuclear catastrophe, and seem willing to exchange these tens of thousands of lives for protection from it. Such a catastrophe, based on 20 years of operation, appears to be more and more unlikely. Based on present evidence, these victims are being sacrificed for nothing.

Sadly, little is being done to educate the public about the scientific basis of nuclear power development and radioactive waste disposal. In my opinion, government and industry should have initiated such educational programs in the 1950s. But it is not too late to catch up. Other nations, notably Canada, have embraced nuclear power enthusiastically, safely, economically, and with broad public support. Nuclear power is the safest form of generally available energy. The task is to build a consensus for its development.

\section{ALBUQUERQUE}

\section{[Continued from Page 1]}

SOI Technologies," is chaired by Hon Wai Lam of Texas Instruments and Malcom J. Thompson of Xerox Corp.'s Palo Alto Research Center. Sessions are offered on SOI for LSI and VLSI, beam-recrystallized SOI, beam recrystallization devices and $3 \mathrm{D}$ integration, polysilicon and polysilicon thin film transistors, thin film technology and large-area applications, and TFT materials.

\section{The Program Chairmen}

The Program Chairmen have long been active in MRS conferences.

Gordon Pike has been especially busy, having served as Co-Chairman of the 1983 Annual Meeting in Boston. With degrees from CarnegieMellon and the University of Pittsburgh, he has spent his career at Sandia, doing research that has ranged from superconductivity and radiation effects in MOSFET transistors to conductive elastomers and electronic properties of semiconductor grain

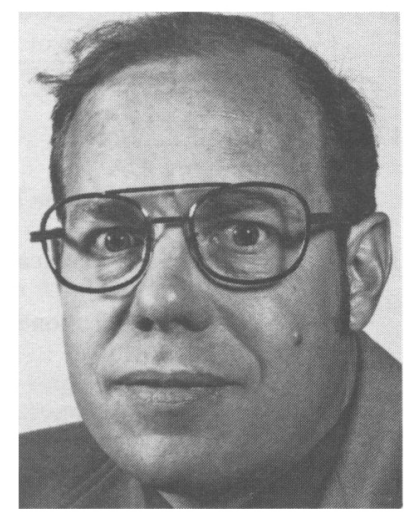

GORDON PIKE boundaries.

Ross Lemons, the inventor of the scanning acoustic microscope, took his Ph.D. from Stanford. Before joining
Los Alamos in 1982, he was a member of the technical staff at Bell Laboratories. His research interests include electrochromic materials, ferroelectric-ferroelastic devices, magnetostatic wave propagation, thin film silicon crystallization, and electrically amplified optical recording.

Noble Johnson, a Co-Chairman of the symposium on energy beam-solid interactions and transient thermal processing at the 1983 MRS Annual Meeting, has a Ph.D. from Princeton. Before joining Xerox, he was associated with the radiation physics group of the Poulter Laboratory of SRI International and with the RCA Research Laboratories in Princeton.

\section{Future Spring Meetings}

West-coast MRS meetings will be held annually in the

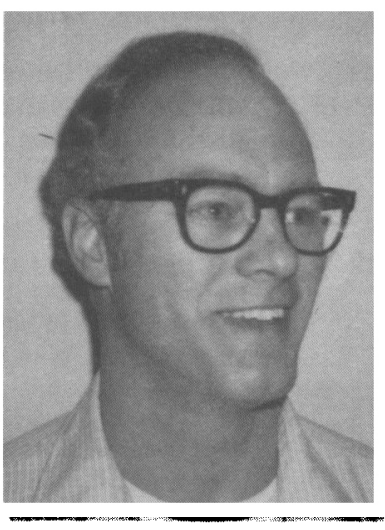

NOBLE JOHNSON spring. As reported elsewhere in these pages, the next one will be in San Francisco. It is set for March 1985. "Together with the expansion of the Annual Meeting in Boston," notes MRS President C.W. "Woody" White of Oak Ridge National Lab, "the Spring Meetings greatly enhance the technical conferences the Society provides to the materials science community. They reinforce our premier position as the professional organization for materials scientists and engineers." 